\title{
The Third Sector and Issues in Civil Society
}

The papers in this issue of the Cosmopolitan Civil societies Journal explore the theme of third sector and community organisations and their engagement with notions of civil society. These organisations are at the heart of civil society, creating spaces for individuals to come together with others to work towards a shared vision for their community. The papers in this issue show the increased diversity and complexity of relationships between individuals, organisations and the wider community. Each provides cases of the pressures, negotiations, resistance, and partnering that characterise volunteer, state, and, corporate interactions in contemporary civil societies. The very different configurations of public action, civil society and community involvement highlight how no single model offers an optimum relationship among civil societies' and the polity other various actors. They also are part of the growing recognition of the importance of 'civil society' both at the domestic and international level for its role not only to promoting civic organisations to become policy participants but also in fostering innovative approaches to improving the well-being and better outcomes for the most vulnerable.

The first paper is by Debal Singharoy, who was a visiting scholar at the Cosmopolitan Civil Society Research Centre in 2010. It reports on a study he conducted into grassroots indigenous organisations and their involvement in environmental issues. Through a series of case studies, he examines the process of articulation and rejuvenation of indigenous identities that negotiate the contending pressures of development and the environment across culture and the needs of the community.

In the second paper, Jonathon Main examines partnerships between organisations within the community services sector. He argues that drivers of collaboration can only be understood in the context of previous interactions between agencies. Whether these were seen as strong, weak or ambiguous was related to whether previous relationships were considered to be disengaged or cooperative in nature. 
In the third paper, Naomi Berman and Emily Mellon focus on individuals, showing how creating space for young social change-makers to develop participatory practices that lead to civic engagement can enhance their sense of self as well as strengthening the community.

Questions of identity are also central to the fourth paper by Ilaria Buscaglia and Shirley Randell. They show how a colonial program intended to empower women in what is now Rwanda undermined the traditional power and authority of women in the society at the expense of creating a Westernised elite. They argue that post-genocide reconstruction of society in Rwanda has established a social and legislative space where the identity of women in society can be reframed.

These four papers continue existing debates and open new perspectives on longstanding questions about how members of democratic societies that value civic engagement interact collectively. These articles show that civil sector organisations do not simply exist in a condition of conflict or partnership with other civil society actors, government and private sectors, but is these relationships are in a state of continual negotiation to create pragmatic solutions to produce and maintain a space for civic inclusion in the polity. We hope that they will spark debate and lead to further scholarly contributions in this important area.

Bronwen Dalton Sydney

February 2012 